
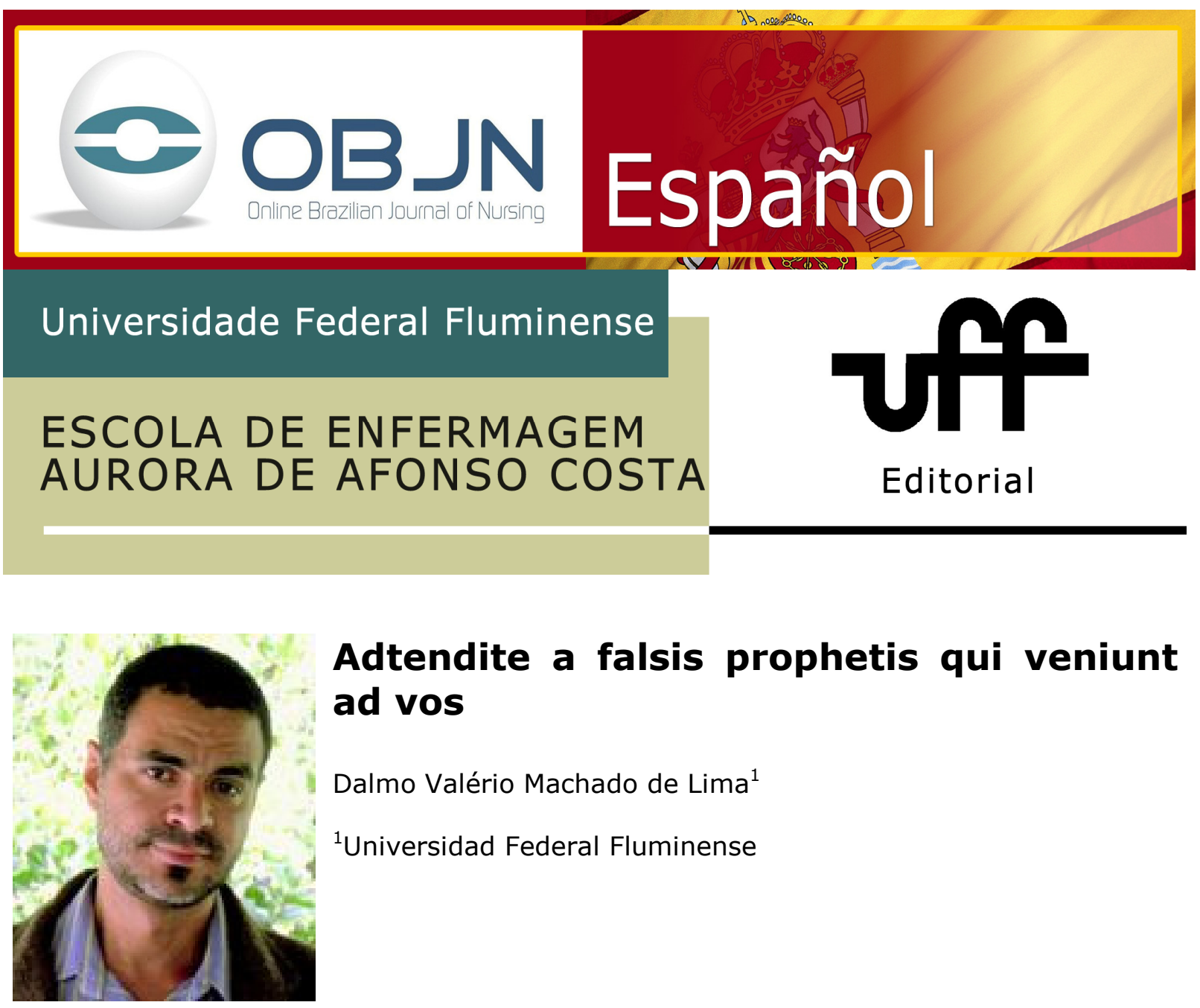

\title{
Adtendite a falsis prophetis qui veniunt ad vos
}

Dalmo Valério Machado de Lima ${ }^{1}$

${ }^{1}$ Universidad Federal Fluminense

RESUMEN: Cada segmento de una sociedad es guiado por parámetros estipulados por instancias reguladoras instituidas por ella misma. En este sentido se establecen leyes, códigos, normas e indicadores de acompañamiento de esa sociedad. Legítimo es afirmar que las leyes deben acompañar al pueblo y no al contrario. Legítimo también es el cuestionamiento de determinados indicadores en cuanto a su real utilidad, así como el contexto en que fueron concebidos y principalmente, ejecutados. Sería razonable, a grandes rasgos, admitir que la mayoría de los indicadores se crean con buena intencionalidad, aunque muchas veces en la práctica, la teoría sea otra. En el campo de la publicación y la edición, la lógica de los indicadores no es diferente. En último análisis, la inserción de un periódico en una base internacionalmente reconocida implica en admitir que él pasó por determinados parámetros de calidad que incluyen: preservación de la ética en las investigaciones y en la publicación, calidad intrínseca del constructo y validad externa de sus resultados.

Palabras-claves: Acceso a la Información; Enfermería Basada en la Evidencia; Indicadores Bibliométricos; Bibliometría; Mala Conducta Científica 
Cada segmento de una sociedad es guiado por parámetros estipulados por instancias reguladoras instituidas por ella misma. En este sentido se establecen leyes, códigos, normas e indicadores de acompañamiento de esa sociedad. Legítimo es afirmar que las leyes deben acompañar al pueblo y no al contrario. Legítimo también es el cuestionamiento de determinados indicadores en cuanto a su real utilidad, así como el contexto en que fueron concebidos y principalmente, ejecutados. Sería razonable, a grandes rasgos, admitir que la mayoría de los indicadores se crean con buena intencionalidad, aunque muchas veces en la práctica, la teoría sea otra.

En el campo de la publicación y la edición, la lógica de los indicadores no es diferente. En último análisis, la inserción de un periódico en una base internacionalmente reconocida implica en admitir que él pasó por determinados parámetros de calidad que incluyen: preservación de la ética en las investigaciones y en la publicación, calidad intrínseca del constructo y validad externa de sus resultados.

Por otro lado, la utilización de determinado indicador de manera inapropiada puede implicar desde la redundancia de información, lo que puede ser considerado un mal menor; hasta el histrionismo de propagar la prestación de un servicio que, efectivamente, no ocurre. Como corolario lógico de esta segunda condición adviene, mínimamente, tres movimientos: el de exposición del propio periódico junto a la comunidad científica; el de debilitación del grupo de periódicos que pasan, a duras penas, las etapas necesarias para la utilización criteriosa del referido indicador y el de proporcionar un pésimo servicio al lector, a medida que afronta su buena fe, rompiendo las barreras entre lo ético y lo antiético, banalizando, en último análisis, la utilidad del propio indicador.

Como plano de fondo de la materia sobre la que trata el presente editorial se toma como ejemplo el Digital Object Identifier (DOI). El sistema DOI fue desarrollado y está siendo implementado en una serie de aplicativos de edición, desde los años 2000. Hasta abril de 2011, más de 50 millones de números DOI fueron atribuidos a cerca de 4.000 organizaciones $^{(1)}$. A pesar de los diversos objetos de atribución del DOI, as aplicaciones de sistema más utilizadas actualmente incluyen citaciones en materiales académicos por medio del CrossRef, un consorcio de cerca de 3.000 editoras. El CrossRef interrelaciona Lima DVM. Internationalization of the nursing for an international nursing publication. Online braz j nurs [Internet]. 2012 Dec [cited year mouth day]; $11 \quad$ (3): $\begin{array}{llll}1-4 . & \text { Available from: } 2\end{array}$ http://www.objnursing.uff.br/index.php/nursing/article/view4136 
millones de ítems a partir de una variedad de tipos de contenido, incluyendo periódicos, libros, anales de conferencias, documentos de trabajo, Informes técnicos y conjuntos de datos. Posee la misión de permitir la fácil identificación y la utilización de contenido electrónico confiable, promoviendo el desarrollo cooperativo y la aplicación de una infraestructura sustentable ${ }^{(2)}$. Entre los servicios del CrossRef se incluye el CrossCheck, que es constituido por un banco de datos de literatura académica que confronta al contenido de su banco contra la sumisión en curso, vinculando autores y títulos previamente registrados ${ }^{(3-4)}$.

De esta manera, la razón de existir una numeración DOI atribuida a un artículo científico es para salvaguardar la legitimidad de los autores que reivindican la autoría del manuscrito, protegiendo autores, editoras y lectores. $Y$, indexar la recuperación de la información con base en una numeración única, interconectada con otras bases de datos, tal como la Plataforma Lattes $^{(5)}$, en Brasil. Sin embargo, no hay restricción en el empleo del DOI en un periódico, aunque la recuperación direccionará hacia el periódico y no hacia el artículo. Por lo tanto, tratándose de indexación del periódico, el International Standard Serial Number (ISSN) atiende perfectamente a la demanda, desde $1971^{(6)}$.

EI ISSN es un código numérico que constituye un identificador unívoco para cada título de publicación en serie cuya atribución es pre-condición para la existencia del propio periódico. Por lo tanto, diferentemente del ISSN que es obligatorio al periódico, el DOI, cuando es adecuadamente empleado, se revela-se un DIFERENCIADO recurso de calidad, de uso opcional y que se destina a la indexación de cada artículo.

La separación del joyo de trigo, como bastante difundido por la cultura hebrea, no necesita efectuarse en la fase de crecimiento de ambos, sino a la hora de le colecta. Pues, al retirarse el joyo se puede arrancar también o trigo ${ }^{(7)}$. No obstante, como bien alerta la referida parábola, nada de eso transcurre sin que el Señor no tenga plena consciencia de lo que está ocurriendo.

Al transportarse los actores referidos por este pasaje bíblico, el Señor es materializado en la figura de los lectores a los cuales se destina la razón de la existencia del joyo y del trigo. Correspondiéndoles la perspicacia de ver crecer juntos dos representantes del mismo reino, aunque de familias distintas.

Lima DVM. Internationalization of the nursing for an international nursing publication. Online braz j nurs [Internet]. 2012 Dec [cited year mouth day]; $11 \quad$ (3): $\begin{array}{llll}1-4 & \text { Available from: } 3\end{array}$ http://www.objnursing.uff.br/index.php/nursing/article/view4136 
Por otro lado, la recurrencia de la presentación de dificultades para la venta de facilidades acompaña al hombre desde los tiempos idos y no cesará, por lo menos en un horizonte breve. En ese sentido, el mismo libro sagrado de los cristianos ilustra una situación en que Cristo recorriendo toda Galilea, enseñando y predicando el evangelio de su reino, avistando la muchedumbre, subió a un monte, se sentó mientras sus discípulos se le aproximaron y les dijo: Adtendite a falsis prophetis qui veniunt ad vos in vestimentis ovium intrinsecus autem sunt lupi rapaces - Tengan cuidado, de los falsos profetas, que vienen hasta ustedes vestidos como ovejas, pero que, interiormente, son lobos devoradores ${ }^{(8)}$.

A pesar de la (a)convicción religiosa de cada uno de los lectores, el contexto de la referida literatura hebrea puede ser perfectamente transportado al cotidiano de cada uno, cabiendo a los consumidores de investigación y a la comunidad científica armarse de aquello que constituye uno de los pilares de la Práctica Basada en Evidencias, cualquiera que sea el acceso a la información.

\section{CITAS}

1. DOI [homepage on internet]. DOI News. April 2011 [cited 2013 Apr 17]. Available from: http://www.doi.org/news/DOINewsApr11.html\#1

2. Crossreforg [homepage on internet]. History/mission [cited 2013 Apr 17]. Available from: http://www.crossref.org/01company/02history.html

3. Crossreforg [homepage on internet]. Crosscheck [cited 2013 Apr 17]. Available from: http://www.crossref.org/crosscheck/index.html

4. Ithenticate [homepage on internet]. [cited $2013 \mathrm{Apr} 17$ ] Available from: http://www.ithenticate.com/

5. Conselho nacional de desenvolvimento científico e tecnológico [homepage on internet]. Plataforma Lattes [cited 2013 Apr 17]. Available from: http://lattes.cnpq.br/

6. Instituto Brasileiro de Informação em ciência e tecnologia [homepage on internet]. Centro Brasileiro do ISSN. Sobre o ISSN [cited $2013 \mathrm{Apr} 17]$. Available from: http://www.ibict.br/informacao-para-ciencia-tecnologia-e-inovacao\%20/centrobrasileiro-do-issn

7. The Holy Bible. King James version. Grand Rapids (MI): Zondervan Publishing House; 1995. Matthew 13: 24-30.

8. The Holy Bible. King James version. Grand Rapids (MI): Zondervan Publishing House; 1995. Matthew 7:15.

\section{Recibido: 17/04/2013}

\section{Aprobado: 17/04/2013}

Lima DVM. Internationalization of the nursing for an international nursing publication. Online braz j nurs [Internet].

2012 Dec [cited year mouth day]; $11 \quad$ (3): $\begin{array}{llll}1-4 . & \text { Available from: } 4\end{array}$

http://www.objnursing.uff.br/index.php/nursing/article/view4136 